\title{
الفكرُ المنهجيّ في التفكير والبحث والسلوك
}

\section{هيئة التحرير}

\section{ما الفكر المنهجيّ}

عندما يفكِرِ الإنسان وَفق منهج، فإنَّ من المتوقع أن يجصل له فكرٌٌ منهجي. وبقدر

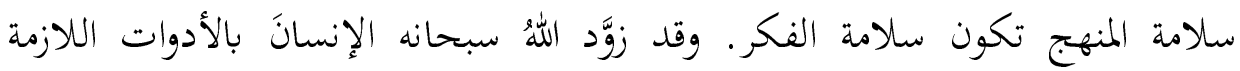

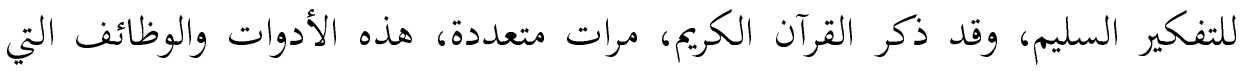

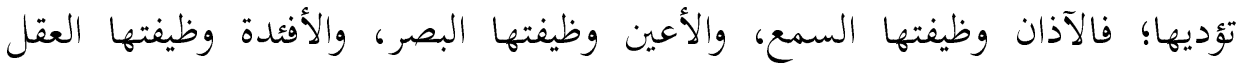

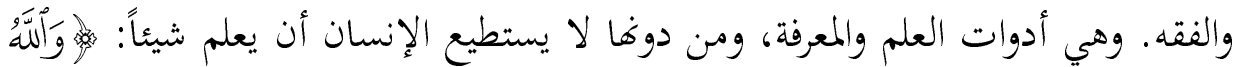

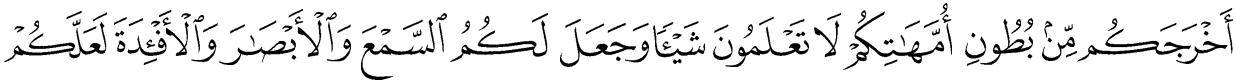

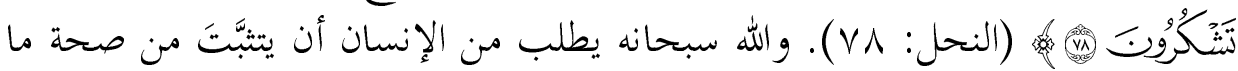

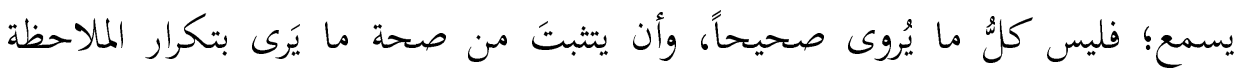

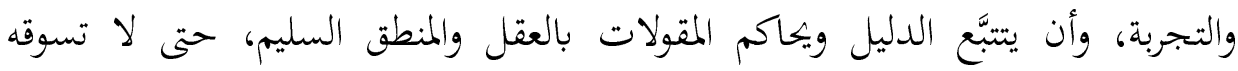

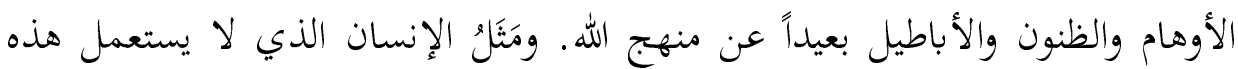

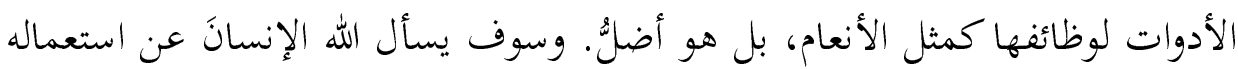

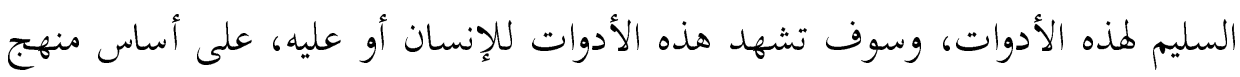
استعماله لما وغرضه من استعماهلها.

فكلٌُ العلوم تحتاج في بنائها واختبارها وتوظيفها إلى منهج. والفكر المنهجيُّ يميز بين مستويات المناهج، وأنواعها، ودرجة توظيفها لأدوات بناء العلم واختباره وتوظيفه؛ فنمَّةَّة

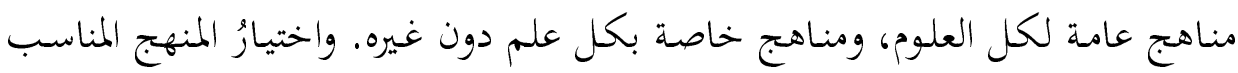

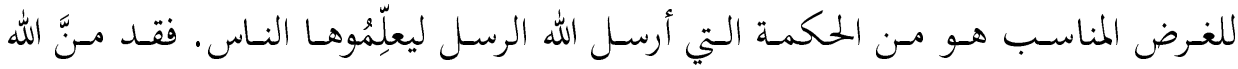

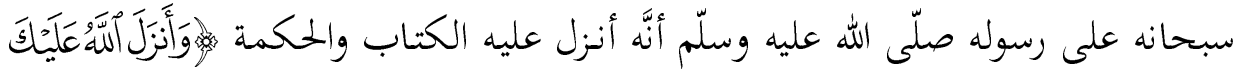

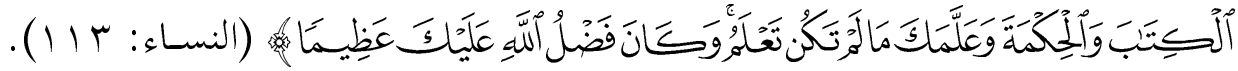


والحكمة هنـاكمـا يقول السعديٌّ في تفسيره: "معرفة أسرار الشريعة الزائدة على معرفة

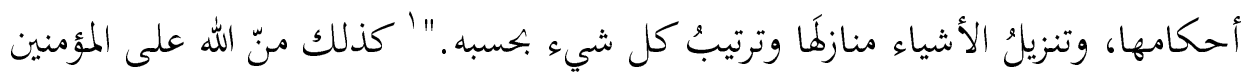

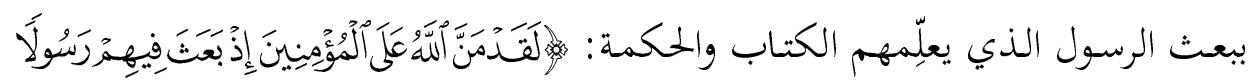

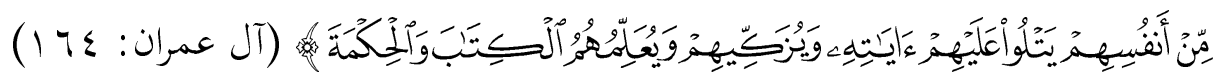
ومن الحكمة اكتسابُ العلم بمناهجه المناسبة له، وفهمُ عناصره وموضوعاته، والتبحُُرُ

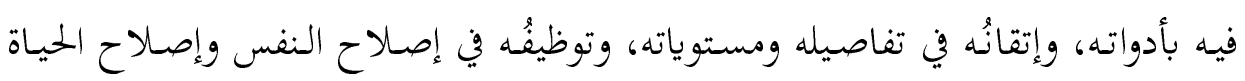

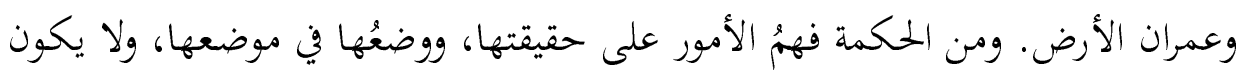
ذلك إلا وَفق المنهج الذي يناسب كلّاً منها.

والسدعوةُ إلى الله تحتساج إلى فكـر منهجسيّ يوظـف المسنهج المناسسب لحسال المسدعوين

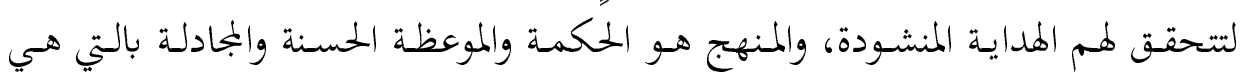

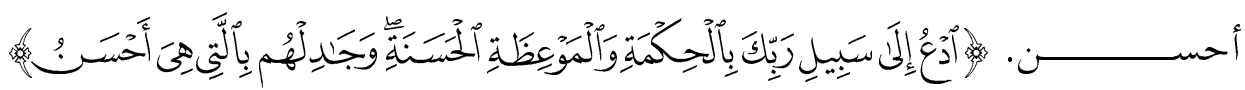

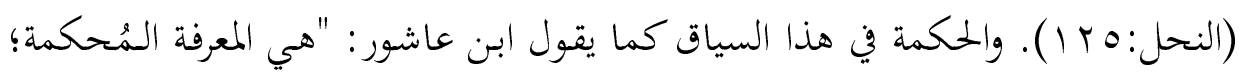

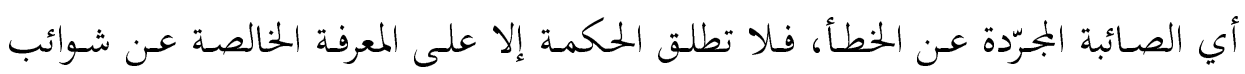

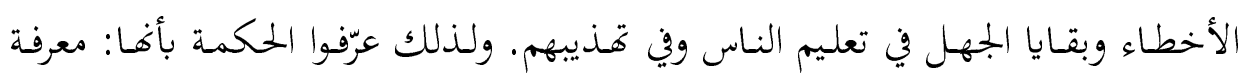
حقائق الأشياء على ما هي عليه، بحسب الطاقة البشرية بحيث لا تلتبس على صاحبها

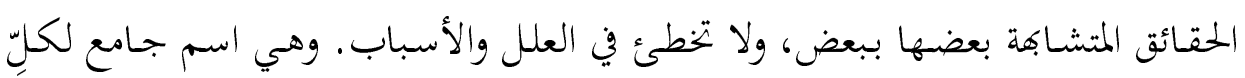

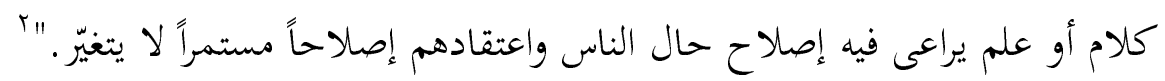
ويمكننا أن نتبـع تطبيقات الفكر المنهجيّ في تطوّر العلوم المنقولة والمعقولة، فعند

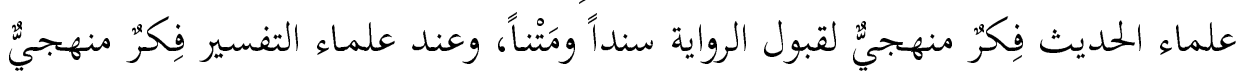

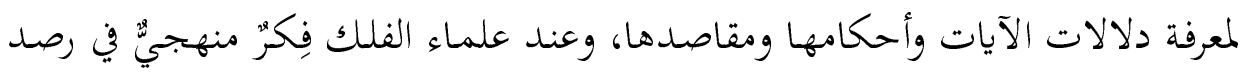

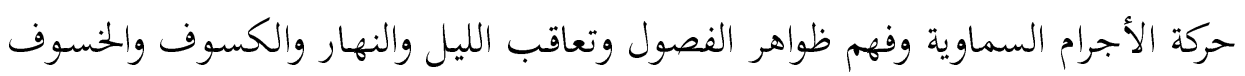

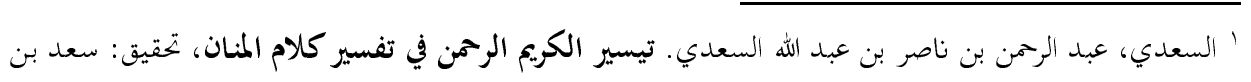

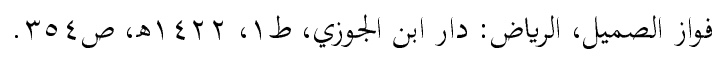

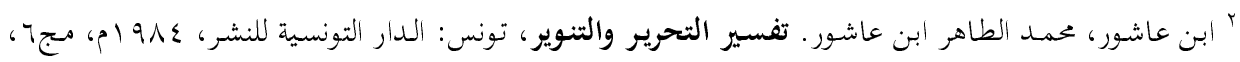


وغيرها، باستعمال المراصد والحسابات، وعند علماء الطب فِكرٌ منهجيٌّ يدرس عوامل

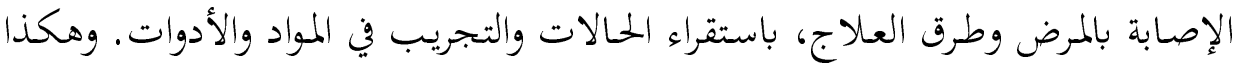
في كلِّ العلوم. ويمكننا أن نتتبع كذلك ممارسة العلماء قديماً وحديثاً للفِكر المنهجيّ. ومع كلِّ ما يمكن أن يقال من تنويه بالمنهج والفكر المنهجيّ، فلا بد أن نقرر بصورة واضحة أنَّ الفكر المنهجي هو في هماية المطاف فكرٌ بشريٌّ، تتفاوت فيه قدرات المفكرين والعلماء وتتنوَّعُ إبداعاهم؛ ففي العلوم النقلية مناهج متنوعة في كلِّ من التفسير والحلديث والفقـه، وغيرهـا مـن العلوم، حتى لو وجـدنا بعض العناصر المنهجية المشتركة فيها. وفي العلوم العقلية كذلك مناهج متعـددة، ونرى الاختلاف والتعدد أكثر وضوحاً في العلوم

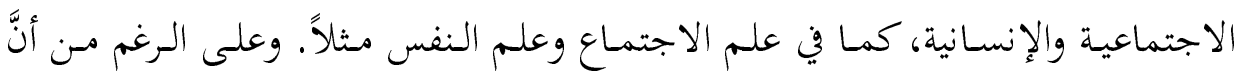

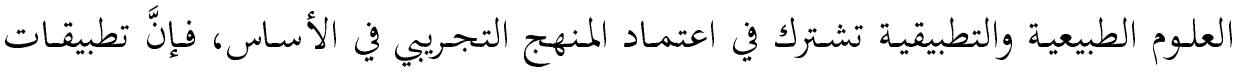
هذا المنهج تتفاوت كثيراً في تصميم مواقف الضبط التجريبي، وكثيرٌ من البحوث التجريبية واجهت نقداً شديداً وتشكيكاً بنتائجها، وكثير مسن الممارسات العملية المبنية على هذهـ المناهج قد تبين الخطأ فيها. لكنَّ وصف الفكر المنهجي بأنَّه جهدهُ بشريٌٌ يخضع للخطأ والصواب لا يقِلِّل من ضرورته وأهميته، وإنَّما يلفت الانتباه إلى عدد من المسائل منها: - أنَّ التعدد والاختلاف في الفكر المنهجي يعدد أحياناً مس ظواهر التنوع المحمود الذي يتناول الظاهرة من زوايا مختلفة ويبعلها أكثر وضوحاً. - أنَّ الإنسان بحاجة إلى مواصلة الاجتهاد والتجديد لترقية الفكر البشري وتطويره

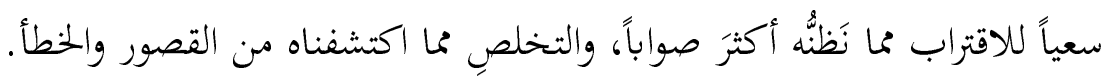
- أنَّ طبيعة الأسئة والمشكلات التي تكون موضوعاً للبحث تكون عاملاً مهمّاً في

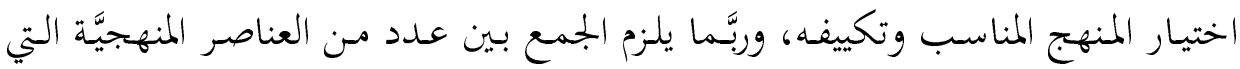
تنتسب إلى فئات مختلفة من المناهج. 


\section{الفكرُ المنهجيُّ في البحث العلمي}

العالمَ المعاصر هو عالم المعرفة الذي تريد كثير من الشعوب أن تعيشه، حتَّى تكون

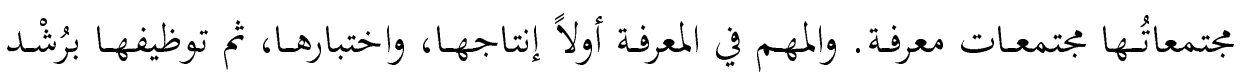
وحكمة، وكلُ ذلك فِكرٌ منهجيُّ.

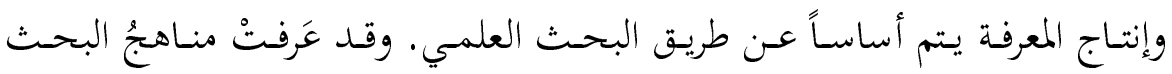

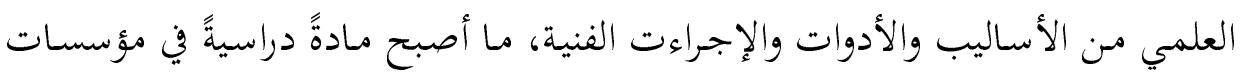

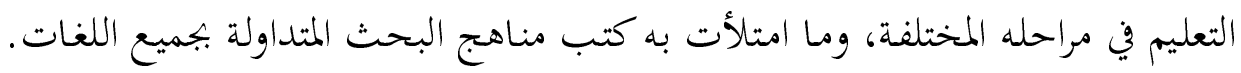

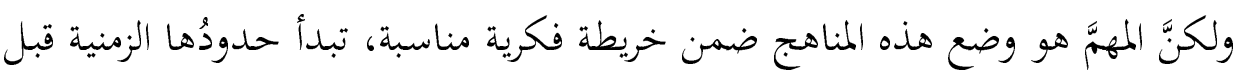

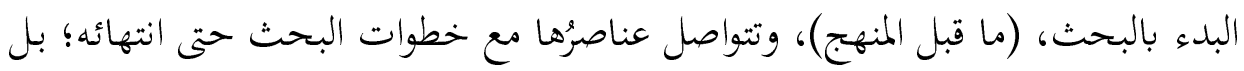

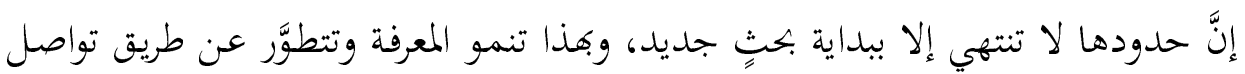

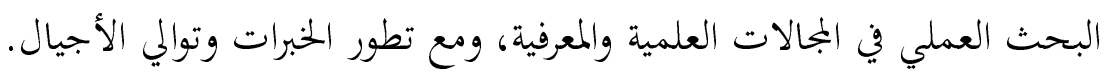

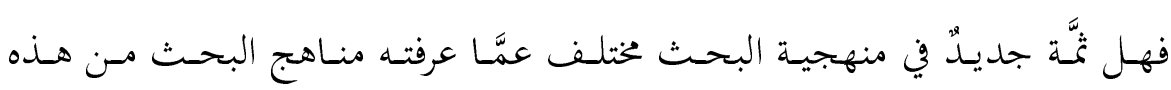

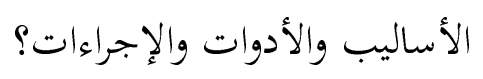

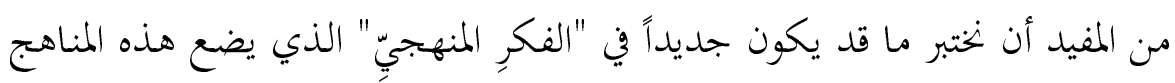

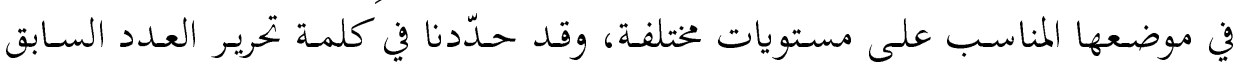

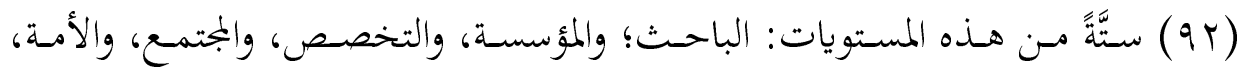

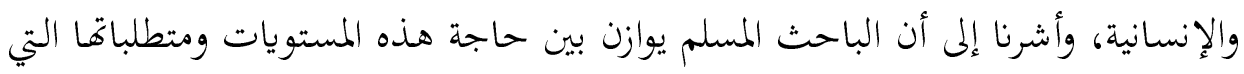

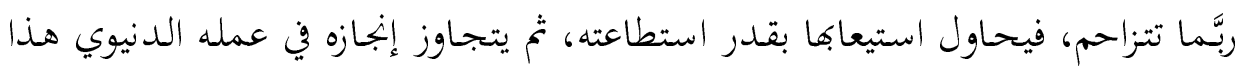
سعياً إلى أجر الآخرة.

وإذا كانت مناهج البحث قد وصلت إلى قدر مسن الاستقرار، مع تطوُّرِ محدود في

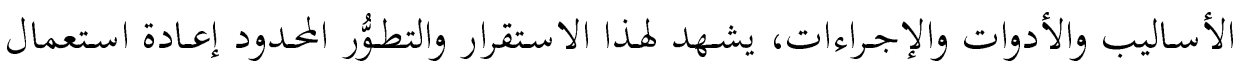

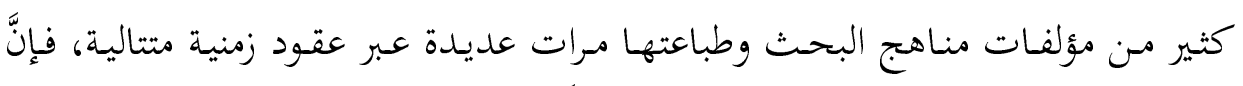

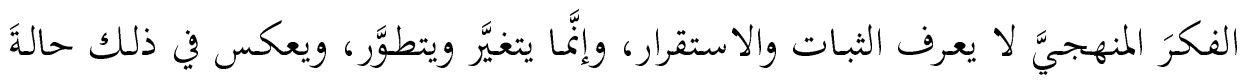

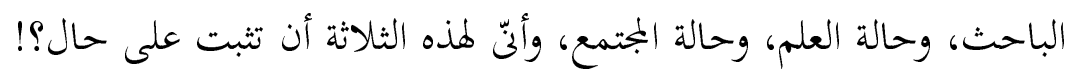




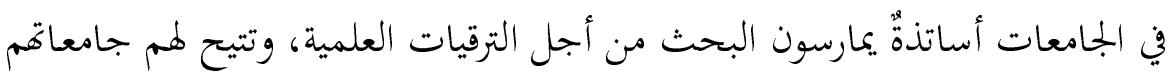

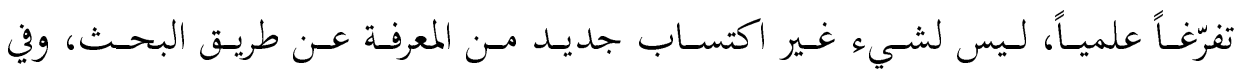

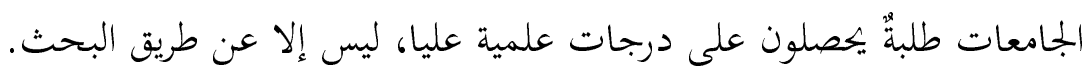
وين معظم الوزارات والمؤسسات أقسام ودوائر متخصصة للبحث في مجالات اهتمام هذه الوزارات والمؤسسات. وفي معظم المجتمعات مؤسسات بحثية متخصّصة ليس لما عمل إلَّا البحث. ويقاس تقدم الدول بنسبة ما تنفقه من موازناتا على البحث العلمي.

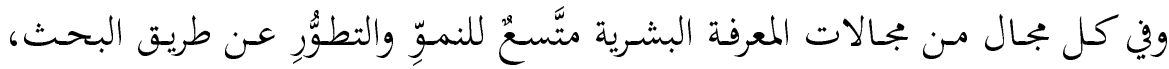

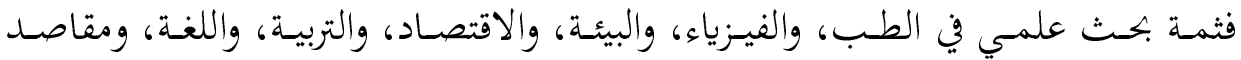
الشريعة، وفقه المواطنة ... وهكذا في كل العلوم الرئيسية وفروعها. وتستطيع أن تتحدَّث باستفاضةٍ وإسهاب عن المجلات العلمية المتخصصة في نشر

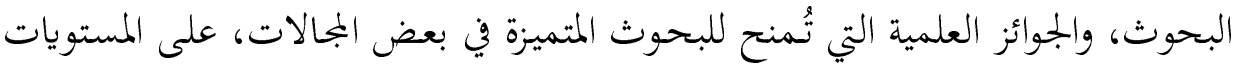

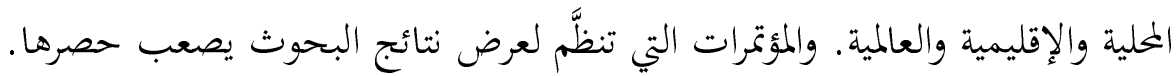
ونسمع في كل يوم عن مكتشفات وصناعات وتقانات جديدة في بجالات الطب

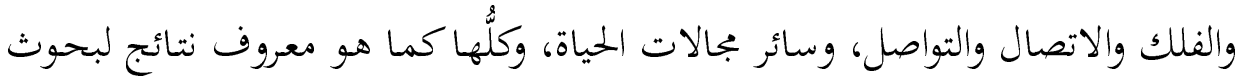
علمية متواصلة.

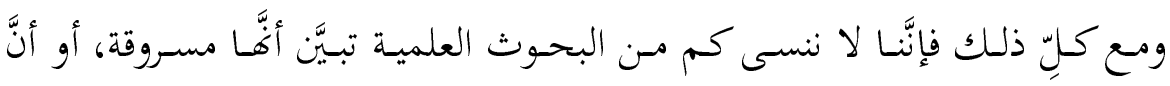

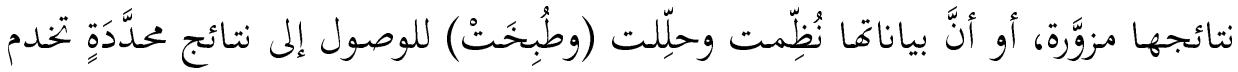

$$
\text { أغراضاً سياسيةً أو تجارية أو حتى أيديولوجية-فكرية! }
$$

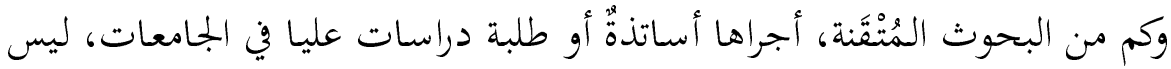

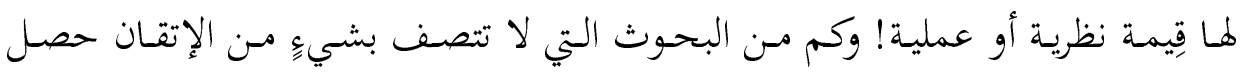

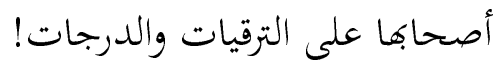

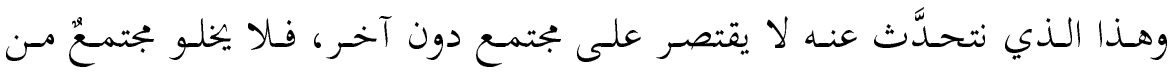

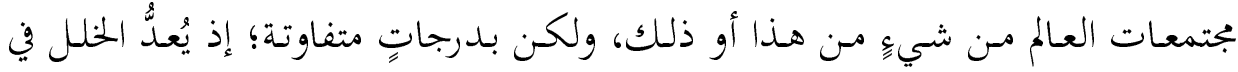




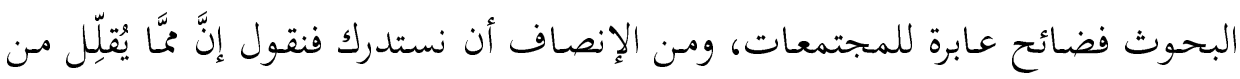

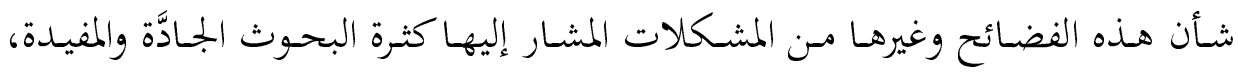

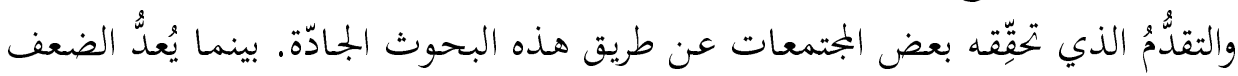

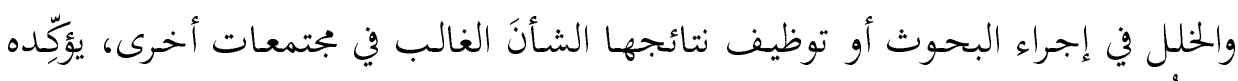

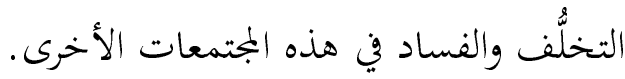

وقـد نظمست لقـاءات ومؤتمرات كثيرة عـن واقع البحتث العلميّ في البلاد العربيـة،

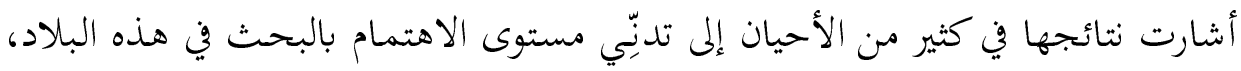

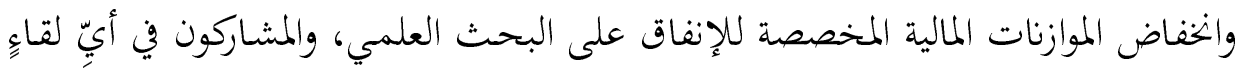

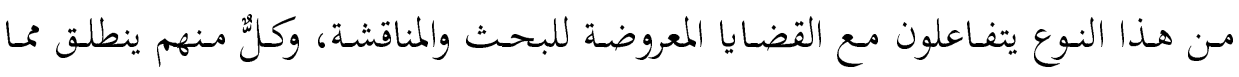

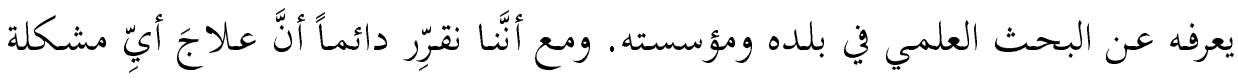

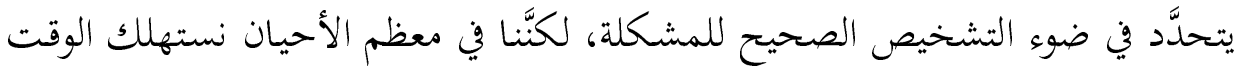

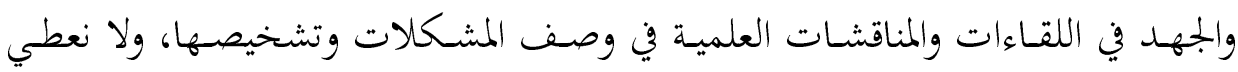
للعلاج إلا القليل! وإثباء الت

\section{مفاهيم المنهج في الثفكير والبحث والسلوك}

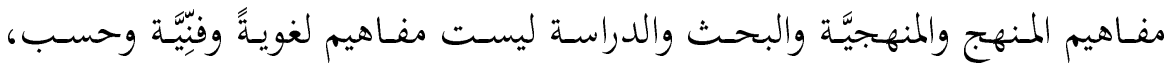

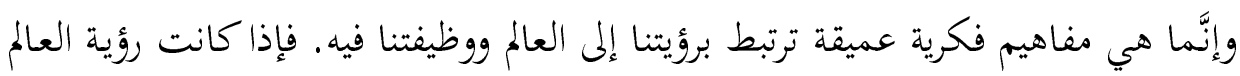

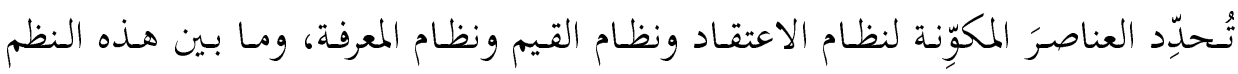

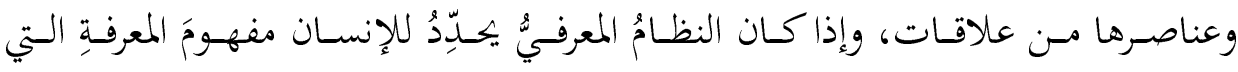

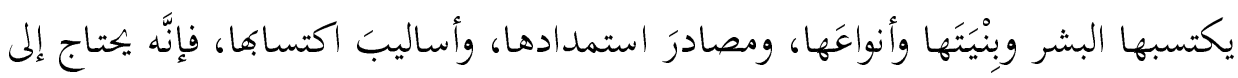

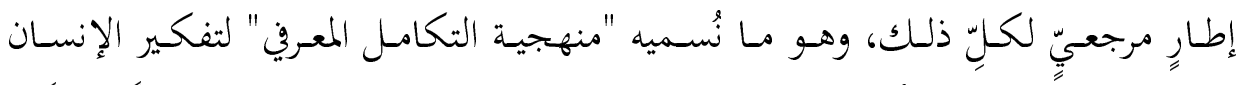

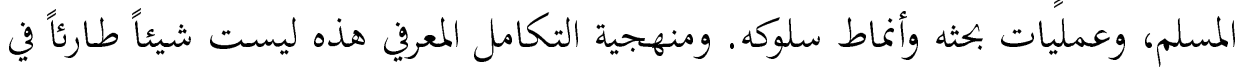

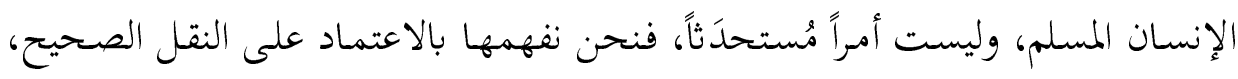

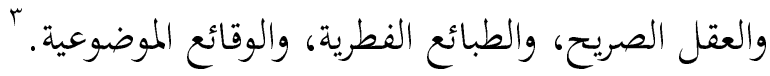

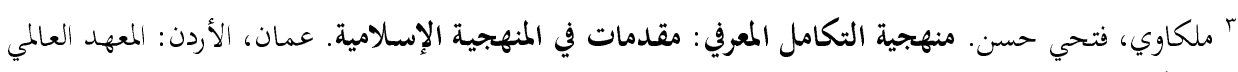

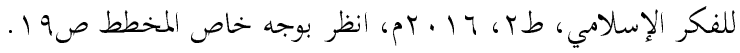


وترتبط مفاهيم المنهج والمنهاج والنهج بحركة الإنسان وتعامله مع الأشياء والأحداث

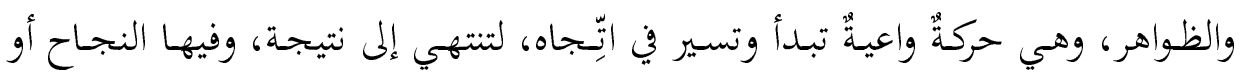

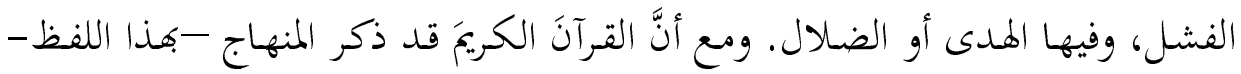

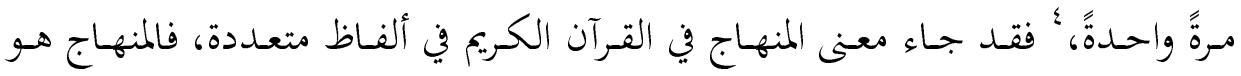

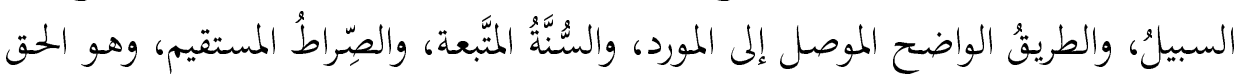

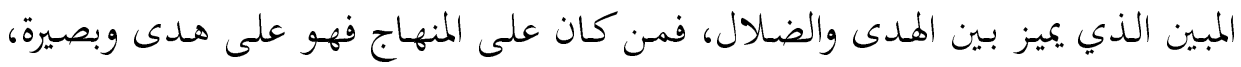
ومن تنكَّه فهو في الضالة والعَمَي.

• فالمنهج في الأساس منهجُ في التفكير، قبل أن يكون أيَّ شيء آخر، فليس ثمَّة

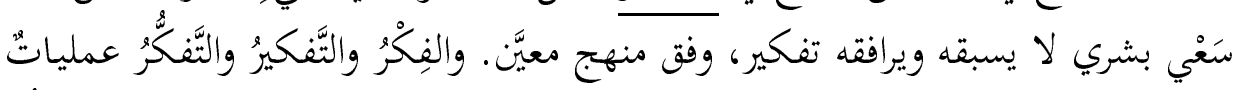

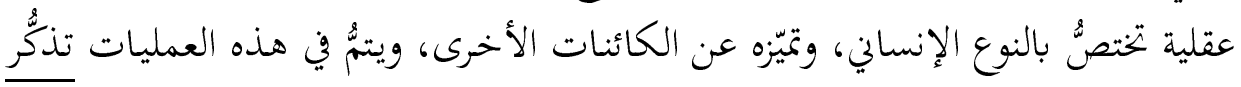

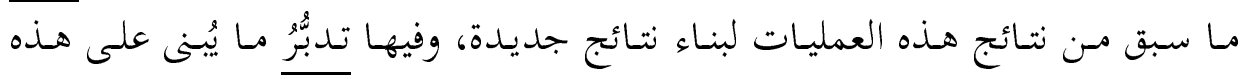

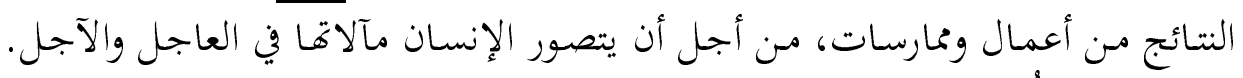

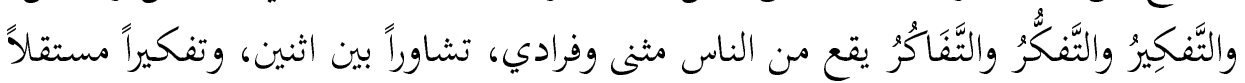

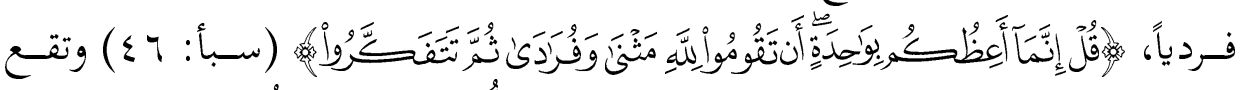

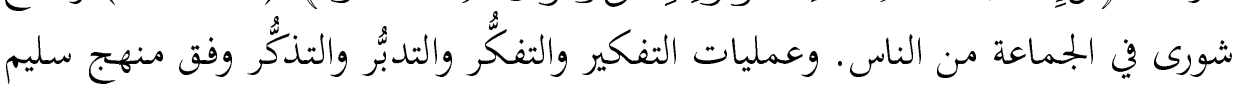

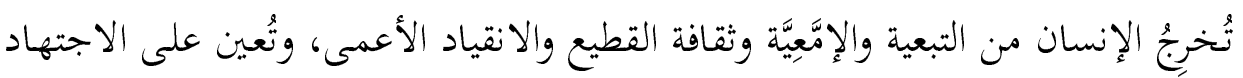

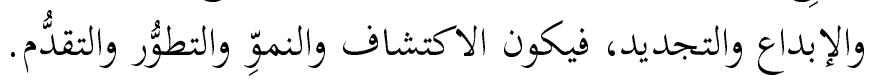

وتتنوَّع منـاهج التفكير وتتعـدّد ضمن فئات ومعـايير مختلفـة، فمنهـ: التفكير البدهِيُّ

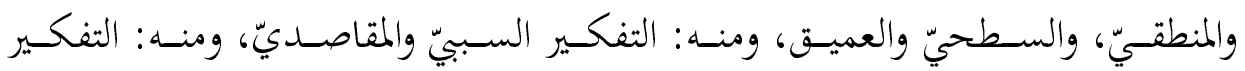

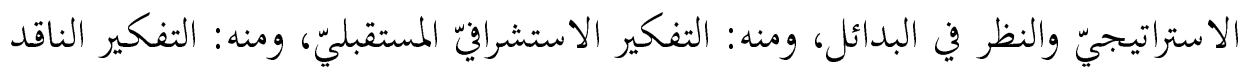

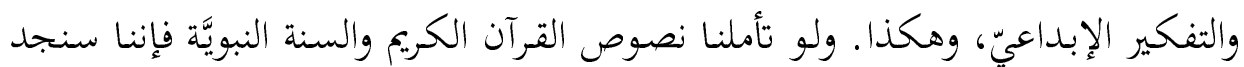

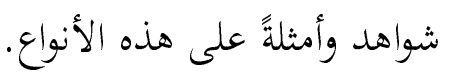

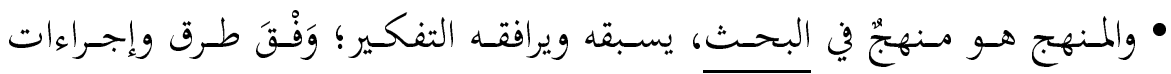

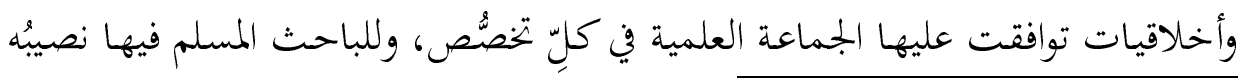

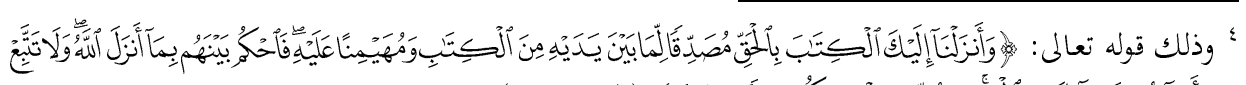

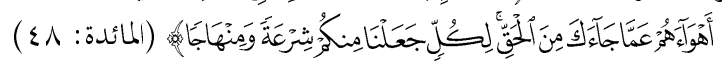


من التوظيف والاستثمار، وله، وعليه الإسهام في التطوير والتميّز والإبداع. والبحثُ فعلو

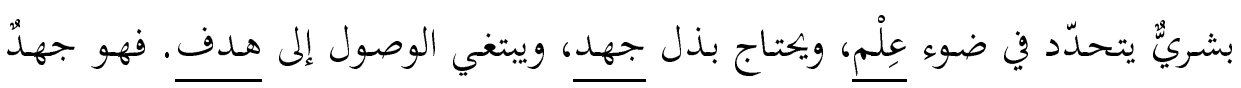

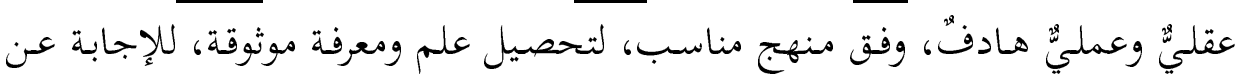

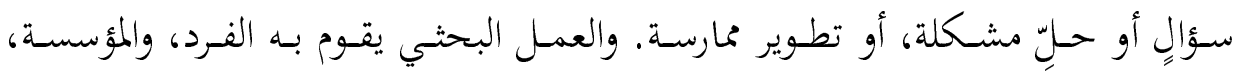

ونُميّز في مناهج البحث بين فئات مختلفة، وفق معايير تصنيف هذه المناهج، فثمَّة

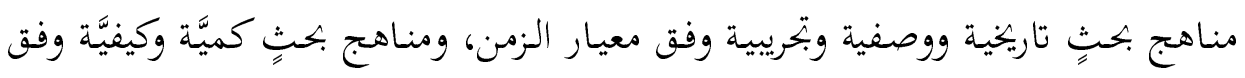
معيار نوع البيانات، ومناهج بحث نظريَّة وتطبيقية وفق معيار الهدف، وفيك، وهكذا.

• والمنهج هو كذلك منهج في السلوك والممارسة والعمل، عندما يتجاوز هذا العمل

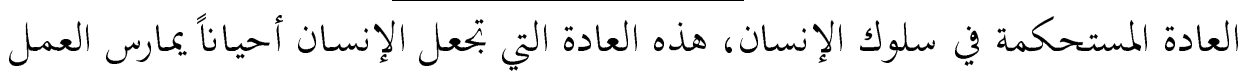

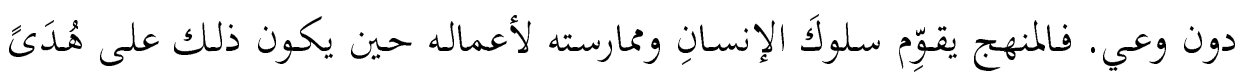

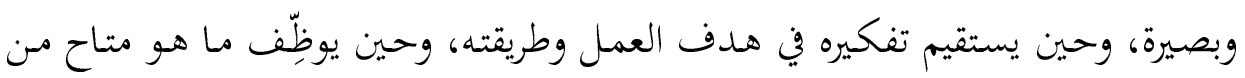

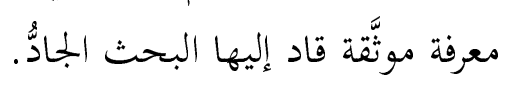

محارسة العمل وفق مـهجج يستدعي مـن الإنسان إرادته لمذه الممارسة، وذاكرته عـن

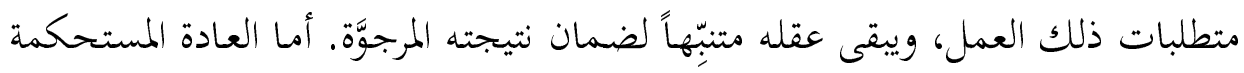
فتأخذ صاحبها في عمل لا تتحكم فيه الذاكرة والإرادة والمراقبة العقلية.

وممارسة العمل وفق منهج يدفع عن الإنسان حالات الانفعال التي يصل فيها حبُّ

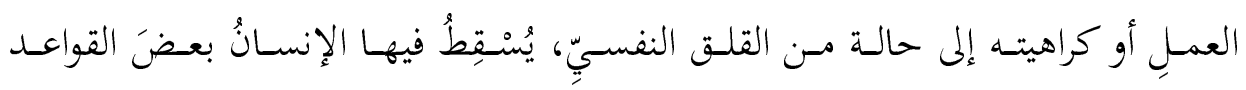
الأساسية في العمل نسياناً أو قصداً.

أجسل! أمَّنْا اليسوم أحسوج مـا تكسون إلى السوعي على المسنهج، وبنساء فكرهـا المنهجي وممارسته في التفكير وفي البحث في السلوك. 